\title{
The GAIA theory: from Lovelock to Margulis. From a homeostatic to a cognitive autopoietic worldview
}

\author{
Luciano Onori · Guido Visconti
}

Received: 31 January 2012/Accepted: 31 May 2012/Published online: 26 June 2012

(C) The Author(s) 2012. This article is published with open access at Springerlink.com

\begin{abstract}
This work consists of two parts. The first presents the state of art concerning the history and the reception by the scientific community of the Gaia hypothesis introduced in the 1970s and which evolved, in time, into theory and quasi-science, i.e., Earth system science. The original Gaia supposes that the temperature, oxidation state, acidity and certain aspect of rocks and waters are at any time kept constant and that this homeostasis is maintained by active biogeochemical feedback processes (first-order cybernetics) operated automatically and unconsciously by the biota. In turn, the probability of life's event and its survival should be linked to processes regulated by the second thermodynamic principle, in its own dynamical equilibrium. This consists in maintaining the organisms at a low level of entropy, through energy-dissipative leakage into the surrounding environment. Life and the environment are so closely coupled that evolution concerns Gaia, and not the organisms or the environment taken separately. Since the end of 1980s, Lynn Margulis, Lovelock's longstanding coauthor, proposed replacing Gaia's homeostatic nature with an autopoietic and evolutionary one that is connected to second-order cybernetic processes. Margulis arrived at the Gaian paradigm shift, mainly based on her authority in the
\end{abstract}

In memory and in debt of University of L'Aquila: Arturo Conte, Professor of Philosophy and Giuseppe Tomassetti, Professor of Physics.

L. Onori

Department of Internal Medicine, University of L'Aquila,

L'Aquila, Italy

G. Visconti ( $\square)$

Center of Excellence Remote Sensing and Numerical

Modelling for the Forecast of Severe Weather (CETEMPS),

University of L'Aquila, L'Aquila, Italy

e-mail: guido.visconti@aquila.infn.it field of the microcosmos. This included symbiogenetic processes concerning the birth and evolution of microbiotic organisms at the planetary level, which led to the construction of macroorganisms and their properties that stabilize the environment. A close relationship between symbiogenetic and autopoietic theory (the latter proposed by Maturana and Varela in Autopoiesis and Cognition: the Realization of the Living, D. Reidel Publishing Co., Dordecht 1980) is represented by the fact that both theories refer primarily to the epigenetic-cytoplasmatic mechanisms in cellular constitution and evolution, and only secondarily to the established, DNA-mediated genetic code. It is the consequent lack of primeval genetic information that requires that both theories postulate the existence of $\operatorname{cog}$ nitive-intentional properties of the living matter (Luisi in Springer 90(2):49-59, 2003) in the construction of the cell and of multicellular organisms. Conversely, traditional theory treats biological organizations as an epiphenomenon, that is, a result of casual processes leading to the constitution of genetic material responsible of cell constitution, duplication and sometime mutation-recombination for new phenotypic forms. The second part of this work consists of more speculative comments about some important articulations of the Gaian construct, in particular: (a) The apparent lack of information on the chemical-physical nature of living and inert matter and on their possible interaction in the construction of organisms and environment. (b) The substantial weakness in the descriptive processes leading to the auto-organization of the two terrestrial matrices (organisms and environment) that is Lovelock's engineeristic and physiological automatisms without consciousness and Margulis' cognitive symbiogenetic processes operating at elementary matter. Both hypotheses have been scantly accepted by established science. The latter appears to privilege the theory of spontaneous and 
istantaneous cooperative phenomenon between elementary particles, at the base of the change from chaos to order and from one ordered state to another, both in physical and living realm. (c) Finally, the substantial underevaluation, operated by Lovelock in his holistic approach to the study of planet Earth, of the role played by the physical phenomenon of the distance interaction between quantum objects, leading to their entanglement. Such phenomena, apparently spontaneous, istantaneous and mediated by quantum field, have questioned the same objective nature of reality. Recently, Süsskind (interviews with P. Byrne, Scientific American, June 2011) noticed that the entanglement phenomenon allows obtaining the knowledge of everything about a composite system without knowing its singular parts: a possible form of holistic approach to planet Earth, well distinct from those proposed by Lovelock and Margulis on solely cybernetic basis.

Keywords Geophysiology - Origin of life - Physics · Geology · Geophysics · Global environment .

Homeostasis - Social sciences

\section{Introduction and Gaia scientific background}

It is likely that in proposing the centrality of biota, among other terrestrial matrices, and its presumed capacity to at least regulate atmospheric composition and temperature parameters, Lovelock and Margulis have been influenced and supported by a set of old and new scientific suggestions such as:

- First, John Hutton (1794) glorious eighteenth century worldview that geological homeostasis was achieved by eruptive phenomena originating within the Earth's interior, as reparation of erosive processes of rocks that would return to the oceans as material weathered from the atmospheric agents and transported there by water runoff. Hutton formulated his hypothesis (obtained during a comfortable boat journey while sailing along the west coast of Wales), by observing that the cliffs appeared to be constructed from vertical stratification of minerals covered by horizontal stratification. From Hutton's theory, Lovelock has borrowed the concept of homeostatic processes in the regulation of the planet and on this principle has centered his construct. To these physical dynamics, Lovelock added the biota role as one important regulatory factor of planet Earth.

- The achievements of Russian biology, historically independent from Darwinism, widely interpreted ontogenesis and phylogenesis on the basis of symbiotic and mutual relationships among primeval bacterial microorganisms and, above all, between the latter and subcellular structures, such as prophages and plasmids originating from plants. While joining rudimentary gene components, such processes could enable microorganisms to reach metabolic autonomy and/or to produce superior organisms, even in critical terms. The same type of evolution may be largely sustained by endogenous mechanisms, i.e., not necessarily determined by the environment: the genome as a unit of selection (Margulis 1989). Thus, early Russian biologists (Famints, Mereschkovskii), introduced to the West by Wilson (1928), are considered to be the founders of "Evolutionary Symbiology". In the Western world, the symbiotic model has been developed in the realm of hereditary and epigenetic systems (Sapp et al. 2002; Margulis 1991), based on a factor of regulation originating from both genic and cytoplasmatic matter (Smith and Szathmáry 1997). This found important support also in Italy, with the extension of the mutualistic-symbiotic paradigm to the vegetable world (Scannerini 1995; Sarà 1994). Sarà (1994) noted that the acceptance of the centrality of symbiotic phenomena is manifested as a global modeling of living beings and is highly relevant to a new holistic approach to nature, according to the Gaian scheme.

In particular, Sonea (1993) (author of a model indicating that bacterial populations may be part of a global system of information, based on cooperation between different, separate units, to the advantage of the mega-organism) considers prokaryotes to be the most coherent manifestation of the Gaian model, as an expression of autoregulation of a complex system through mutualism. We will see later that, through her symbiogenetic approach to life, Margulis made an important theoretical contribution to the Gaian construct, facilitating the acceptance and confluence of Gaia in the autopoietic theory (Maturana and Varela 1980).

- The triumph of the information/decision theory that could enlighten the flow of information circulating through living beings in the biology field has two sources:

a. Genetic inheritance (genome), whose genetic information is subject to feedback control, according to F. Jacob and J. Monod.

b. Sensory receptors that all organisms, from bacteria to the whales, possess.

The information-decision theory could also help to understand the close interactions and mutual control that exist between the animate and inanimate worlds. However, it does not play a crucial role in Lovelock's Gaian construction. Even so, Lovelock does give importance to the analogy between the ability of a living organism (Schrödinger 1944) and communication systems (Shannon 
and Weaver 1949) to maintain life and low entropy levels, mainly through a continuous energy leakage into the surroundings.

- The catastrophe theory (Thom 1989), applied in biology and geophysics, will allow Lovelock to further hypothesize a synchronic form of evolution "by jumps", and not necessarily a "diachronic" or continuous kind, which in the long term was suggested by Darwinian theory. In this way, Gaia theory predicts a kind of evolution that is not only intermittent, but also fast and abrupt, representing "discontinuity". Even so, Lovelock considers evolutionary discontinuity in terms of a given state's modification of the environment and of living beings proceeding together, as "a whole", as predicted in his holistic vision. Thus, if there is evolution, it is only attributable to Gaia. ${ }^{1}$ Here, Lovelock probably expresses his greatest compliments to his creature, assumed to be the only possible expression of evolution on the planet.

- General systems theory (Boulding 1965) is a term that has come into use to describe a level of theoretical mathematical models linking specific theories of several different disciplines, such as cybernetics, information theory, organization theory, autopoietic theory, and so on, with applications to several fields. Thus, Ludwig von Bertalanffy (1968) (author of the theory) defines the systems theory as a general science of "wholeness", as a means to achieve an exact theory in natural and social living realities, whose very nature and definition are not those of closed systems. Closed systems do not exchange matter with their environment, but are in true equilibrium and conserve mass (according to classical physics concepts). Consequently, in the past, science tried to explain observable phenomena by reducing them to an interplay of elementary units investigable independently of each other. We now know that each living organism is essentially an open system. It maintains itself in a continuous inflow and outflow, in a binding up and breaking down of its material components, in a chemical or thermodynamic equilibrium. Thus, a system may be defined as a model of a set of elements interrelating between themselves and with

\footnotetext{
${ }^{1}$ In the history of co-evolution of the environment $(E)$ and the organism $(O)$ (but not in a holistic vision), we found Lewontin's (1998) well-known opinion summarized in a two-coupled equation:

$\mathrm{d} E / \mathrm{d} t=f(O, E)$.

$\mathrm{d} O / \mathrm{d} t=g(O, E)$.

Here, the history of the environment and that of the organism are a function both of the environment and the organism, and the two equations must be solved together constituting a one, indivisible couple, which describes the co-evolution of the environment and the organism in which they are both causes and effects.
}

the environment, within a super-ordinate "whole." The notion of a system includes the internal description of intrinsic organizational properties in terms of state variables and their interdependence. On the other hand, in the external description of the system's behavior, it is viewed in terms of its interaction with the environment, through a functional boundary between the two components. Thus, a basic problem posed to modern science is a general theory of organization.

As with Scannerini (2003), Gaia appears to be an example of the general systems theory. As we will see, however, Lovelock has chosen an approach that requires minimal internal organization, postulating a low level of conflict between the biosphere and in general living components and environmental elements. Conversely, according to von Bertalanffy (1968) and Luhmann (1984), the environment has a higher level of complexity, in comparison to that of system sensu strictiori (including human species and its social organization), requiring its continuous and tight functional control by the latter. This is actually the biggest critique to Lovelock's theory, whereby the reduction of conflict and the substantial harmony, reigning on the planet, is the only way it can be called Gaia (Kump 2009).

- Modern physics, specifically quantum mechanics, plays virtually no role in the Gaian construct. Conversely, the most general principles of the scientific explanation of the natural world are: (1) quantum conception, (2) the second principle of thermodynamics and (3) selforganization in physical and nonphysical dynamical systems (Azzone 2010; Haken 1975). ${ }^{2}$ The latter is observable either by reducing the problem to a few collective degrees of freedom, according to the usual strategy in physics, or conversely leaving dissipative dynamic systems to naturally evolve into a critical state where the organization of different species of a system "support" each other in a way that cannot be

\footnotetext{
2 Among physical systems, examples of dynamic self-organization arising from cooperative mechanisms are the well-known Ising model of the ferromagnet behavior, the laser effect, or the superconductor which behaves as a quantum system with a macroscopic wave function. Similarly the convective motions arising in fluids from thermal gradients form regular structures: the so-called Bénard cells. Conversely, examples of nonphysical systems are, intuitively, formation of public opinion or actions of social groups. Similar mechanisms sustain the creation of neuron networks as observed in the cerebral cortex. The latter follows from the cooperative activation of one nerve cell through the reception of neurotransmitter signals from several nearby cells within a time interval equal to or less than $10 \mathrm{~ms}$ (Haken 1975). Furthermore, according to Cherniak (2005), complex biological structures appear to arise directly from basic physics: nerve cells anatomy behaves like flowing water and water flow in turn acts like a tree composed of springs.
} 
understood by studying the individual constituents in isolation (Bak et al. 1988).

Lovelock explains practically everything based on the second principle, while almost completely neglecting the atomistic world. Lovelock's deafness to suggestions coming from quantum mechanics may come as a surprise, particularly considering that the young Lovelock was lucky enough to participate in a course by Erwin Schrödinger in Dublin (1943), while the latter was publishing his famous booklet "What Is Life?" (Schrödinger 1944) In this book, the quantum physicist established the quantum basis of biophysics, biochemistry and biogenetics, and predicted Crick and Watson's discovery of the structure of DNA 10 years in advance.

Taken together, the previous reference to Gaia's background appears to be unifiable by a sort of "a family air", in Wittgenstein's words, consisting in their being largely incompatible with neo-Darwinian synthesis.

Clearly, it is not a deadly sin, in and of itself, to tune a statement into the growing secular criticism of Darwinian intuition regarding the overwhelming role of natural selection in the evolutionary processes of biota and the environment. What is disturbing, however, is that Lovelock and Margulis assume the role of natural selection in biological evolution to be marginal or irrelevant, a role acknowledged even by the most severe critics of neoDarwinism. $^{3}$

\section{The birth of Gaia}

We would like to think that the Gaia hypothesis, which became theory and finally science, or quasi-science, in just a few years, sprung forth as a reaction to the deathly intellectual and spiritual boredom and tedium of its promoter, James E. Lovelock, inside a NASA laboratory during the 1960s, in the middle of the Cold War era. At that time, the sky was perhaps more leaden than ever, almost entirely concealing to mortals the vision of what Saint Augustine called the "heaven of the heavens", the celestial vision of the angels, or alternatively, of the pagan gods,

\footnotetext{
3 To this end, Kauffmann (1993) states that "the most persistent critics have been the neutralistic ones (Kimura 1983), who argued that much of evolution, at the molecular level, is selectively neutral. At the macroscopic level two issues: (1) the problem of morphological stasis and punctuated equilibrium, and (2) species selection rather than individual selection have challenged neo Darwinism. However, my own aim is not so much to challenge as to broaden the neo-darwinian tradition". Briefly, the latter today seems inadequate to entirely explain, on its own, the evolutionary origin of complex wholeness.
}

which could be preferable to the Hebrew-ChristianCalvinist God, who was too closely implicated in the unattractive and predatory history of Western man.

In those years, James Lovelock was appointed by NASA to investigate the chemical composition and physical characteristics of the atmosphere surrounding Mars, in order to determine the planet's suitability for life.

Lovelock accepted the assignment, even though he was sure that there was no life on Mars. ${ }^{4}$ In fact, in the mid1960s, even before NASA sent the Mariner probe to observe the desolate surface of the planet from orbit, observations had been carried out from Earth with infrared telescopes, showing that the atmosphere on Mars, as on Venus, was dominated by carbon dioxide and only a small percentage of oxygen and nitrogen. Even more importantly, there was a chemical balance among these gases. ${ }^{5}$ The latter is usually considered a typical characteristic of environments in which the chemical-physical balance is not disturbed by elements produced by the metabolism of living beings, but is regulated on the basis of strict chemical-physical stoichiometric reactions leading to optimal equilibrium.

It must have been right that Lovelock was considered a sort of devil's advocate in his circle in the NASA Jet Propulsion Laboratory, where he had his own "revelation", as he will himself admit. At that time, the agreed notion in evolutionary geobiology was that chemical-physical conditions of the atmosphere, including temperature, determined a planet's livability.

Lovelock could turn the terms of the problem upside down in this way, given the clearly evident and indisputable fact that there is life on Earth. Thus, life could have contributed to creating an atmosphere that is completely different and almost complementary to the ones on Mars and Venus, and predictably, with chemical, physical and thermal disequilibrium. Lovelock does not seem to indicate whether the creation of a particular kind of atmosphere by life is due to chance or necessity. Indeed, a single example

\footnotetext{
${ }^{4}$ Clearly, a prior denial of the possibility of life on Mars created much chagrin at NASA, who gave Lovelock one research contract instead of two.

5 According to paleogeochemical evidence, molecular oxygen was present in only trace amounts even on Earth. Based on recent phylogenetic and enzymatic geochemical resources, it has recently been proposed (Ducluzeau et al. 2008) that in the earliest Archean era, nitric oxide (NO) and its derivatives (nitrate and nitrites) served as oxidizing substrates, driving the evolution of a bioenergetic pathway related to modern dissimilatory denitrification. Aerobic respiration emerged later from within this ancestral pathway via adaptation of the enzyme NO-reductase to its new substrate, bio-oxygen.
} 
of a given phenomenon cannot be of any real help in deciding whether it came about by chance. ${ }^{6}$

\section{The formal theory and its critics}

Lovelock's Gaia is a particular type of open thermodynamic system that is planetary in scale and has abundant life tightly coupled to its environment. Planet Earth hosts the only known example for which the name "Gaia" could apply (from the Greek mythological Gea, Mother Earth, generous giver of life).

Gaia theory covers over 3.5 billion years of the Earth's history. Focusing solely on the coming centuries and on the past, roughly 1 million years would unlikely give a representative picture, especially as we happen to live at an unusual time of transition. More generally, it is possible that positive biological feedback with the environment dominates on shorter timescales and that negative feedback dominates on larger timescales (Lenton and Wilkinson 2003; Kleidon and Fraederich 2004) "Homeostasis" and "punctuated equilibria" have both been applied to Gaia in an attempt to describe the notion of long intervals of relative stability (predominance of negative feedback), interspersed with shorter transitions (predominance of positive feedback). In particular, such diachronic dynamics between feedbacks of the opposite signs would be inferred by the record over remarkably constant bounds of temperature, $\mathrm{CO}_{2}$ and $\mathrm{CH}_{4}$ within the glacial cycles. The hypothesis that life increases the resistance of the Earth's system (Lenton 2002) leads to a similar hypothesis that negative feedback is stronger in the presence of life, but it was not meant to be a universal generalization. Many (and perhaps most) globally important biotic feedbacks appear to be based on by-products of selection (Lenton 1998; Volks 1998, 2004).

\footnotetext{
${ }^{6}$ More in general, T. C. Chamberlin, American geologist, who is best known for his contribution to the "Chamberlin-Moulton hypothesis" of the origin of the solar system, at the beginning of the twentieth century says "our trouble is that when we make a single hypothesis, we become attached to it. To avoid this grave danger, the method of multiple hypotheses is urged". This systematic method of inference (known as strong inference) in comparison to single working hypothesis (weak inference) consists of applying the following steps to every problem in science:
}

1. Devising alternative hypotheses.

2. Devising a (or several) crucial experiment with alternative possible outcomes, each of which will exclude one or more of the hypotheses.

3. Carrying out the experiment so as to get a clean result.

This algorithm is tree like, in that there are right and left branches which are similar to branch points in a "conditional computer program", where the next move depends on the result of the last calculation.Molecular biology is a field where this systematic method of inference has become widespread and effective (Platt 1964).
Thus, Gaian evolution would result from feedback operated by organisms emerging from natural selection with inorganic components (Lovelock 1988). ${ }^{7}$ This is actually the major difference between the Darwinian concept of evolution and Lovelock's idea of evolution. The resulting type of regulation often maintains that an environment is viable in a limiting state, which in turn can be remarkably "resistant" and "resilient" when faced with perturbations, compared to feedbacks that would exist in an abiotic state.

The Gaia hypothesis presents a new view of the atmosphere, which is seen as a component part of the biosphere rather than a mere environment for life. In this new context, the incompatibility between the biological cycle and inorganic equilibria is seen as more apparent than real.

In general, theories are considered to be worldviews, often presented in the form of metaphors (see J. Lacan's definition "un mot pour un autre mot", one word for another), and are presumed to be untestable in that they include assumptions and definitions. Theories, however, may be fruitful, as they include mechanisms and testable processes. In particular, Gaia theory has been considered ill defined and difficult to test, mainly regarding the need for optimization of the environment by biota for its own benefit (Kirchner 1989; Kleidon 2002). Kleidon, for example, asks "What is beneficial? What is good for one species may be bad for another". 8

Concerning the testability of Gaia, it is particularly useful to consider certain seminal papers.

Kirchner (1989) starts by defining a weak form of Gaia, which holds that life collectively has a significant effect on the Earth's environment (influential Gaia), and that therefore the evolution of life and of its environment are intertwined, with each affecting the other (co-evolutionary Gaia). Kirchner argues that abundant evidence supports these weak forms of Gaia, and that they are part of a

\footnotetext{
7 In this contribution, several citations from Lovelock's ample literary works are taken from The Ages of Gaia, which seems to be the most speculative and least esteemed of the author's references.

${ }^{8}$ The main criteria of hypothesis testability are summed up in the following:

- A hypothesis must be clear and its terms unambiguous.

- It must be intelligible and based on observed phenomena.

- It must generate predictions of two types: (A) confirmatory predictions (for phenomena that should be observed if the hypothesis is true and that would not be predicted by the existence of a body of accepted theories); (B) falsifying predictions (phenomena that should be observed if the hypothesis is false).

- The hypothesis in each of these logically distinct classes will usually show good agreement with experimental data.
}

At least, the second and third points refer to criteria not observed in the Gaia construct (Kirchner 1989). 
venerable intellectual tradition (Spenser 1893; Huxley and Thomas Henry 1887; Harvey 1957).

By contrast, the stronger forms of Gaia depart from these traditions, claiming that the biosphere can be modeled as a single giant organism (geophysiological Gaia), or that life optimizes the physical and chemical environment to best meet the biosphere's needs (optimizing Gaia). Here, Kirchner argues that stronger forms of Gaia may be useful as metaphors, but are unfalsifiable and therefore misleading hypotheses. By definition, a hypothesis is considered misleading when one believes it fits the data well, because it captures the essence of the problem, when actually it fits because it is independent of empirical facts (Kirchner 2003).

Kineman (1997) prefers replacing the "weak Gaia" versus "stronger Gaia" nomenclature with the labels of the original Chapman Conference "ecological Gaia" and "evolutionary Gaia", in order to highlight an important philosophical split within the biological sciences. In this new formulation, "ecological Gaia" replaces the influential, stabilizing and co-evolutionary taxonomies proposed by Kirchner (1989), while "evolutionary Gaia" involves a view of life as a creative and active agent. The latter Gaia view implies a general principle that life is fundamentally self-organizing and, in the strongest sense, fundamentally self-determining.

\section{Daisyworld: can a mathematical model support a theory?}

In addition to the problem of the testability of Gaia, Lovelock found additional difficulties in defending the same theory when he tried to support it through the construction of a mathematical model (i.e., Daisyworld). In this model, Lovelock operated a drastic simplification: the environment is reduced to a single variable (temperature) and the biota to single species (daisies). Lovelock (1988) naively states that the construction of Daisyworld was "at least at the beginning, some sort of an answer to a critique. I have formulated it to this end. But as soon as I improved the model, I discovered that the model was a source of revelations that constituted an answer to the questions on theoretical ecology and Darwinism besides the questions over Gaia". These considerations regarding the use of a model are surprising, in that geochemical models require thermodynamic and kinetic data that are incompletely or only approximately known; and even when such measurements are available, they are never available for all model elements (Tsang 1991). Another reason why hydrological and geochemical models are never closed systems is that the observations and measurements of both independent and dependent variables are laden with inferences and assumptions. ${ }^{9}$ Today, there is widespread agreement (mainly regarding managing complexity) on the notion that numerical tools offer essential insight and they are often very useful in quickly identifying invalid or weak hypotheses. Thus, it is the deeply revealing insights gained from analytic methods, such as statistical and dynamical analyses, that ultimately lead to the most transformative discoveries Chassin and Posse (2004).

In this case, Daisyworld is a model planet with black and white daisies with separate fitness curves, in which the black ones like it cooler and the white ones like it warmer. As the sun heats up over 3.5 billion years, black daisies approach their optimum temperatures, become more fit and thereby increase their population, causing the albedo (reflectivity) of the planet's surface to drop. This is positive feedback, because while more sunlight is absorbed by the dark flowers, the planet further warms. Black daisies increase until the temperature surpasses their fitness peak and moves into the fitness range for white daisies. These then begin to multiply and replace the black daisies. This shift increases the planet's albedo, which serves as a negative feedback on further warming. The planet's overall temperature is stabilized for eons, even as the sun inexorably increases its luminosity.

At this point, however, Schneider (2001) argues that the white daisies are probably heated past their fitness range and would not resist further warming. The biota should then collapse and the temperatures rise rapidly. Furthermore, Schneider points out that on real Earth, vegetation albedo has a relatively weak effect on climate, because clouds and haze cover most of the surface. In the same direction, Kirchner (1989) notes that vegetation's response to temperature is weaker on the real Earth than on Daisyworld, where a temperature shift of only $1{ }^{\circ} \mathrm{C}$ can expand daisy cover from 0 to $45 \%$ over the planet's surface. On the real Earth, vegetation would actually respond to temperatures in the opposite direction from what Daisyworld predicts; all else equal, warmer temperatures would expand forests poleward, making the surface darker and thus amplifying the warming (Kirchner 1989).

\section{From Lovelock to Margulis, from first to second cybernetics}

Since the initial proposal, Gaia has proceeded somehow in two different directions. On the one hand, Lovelock's

\footnotetext{
9 According to Oreskes et al. (1994) observations: "verification and validation of numerical models of a natural system are impossible ... Models can only be evaluated in relative terms, and their predictive value is always open to question. The primary value of a model is heuristic. In fact, a model is usually used to confirm our biases and to support incorrect intuitions. Therefore, models are most useful when they are used to challenge existing formulations rather than to validate or verify them. Any scientist who is asked to use a model to verify or validate predetermined results should be suspicious".
} 
approach, which is mainly physiological and engineering in nature, is based on exchanges of fluxes of matter and energy (with positive and negative feedbacks) between living organisms and inanimate components of the planet. These exchanges take place in a way that especially guarantees planetary homeostasis, rather than its evolution. On the other hand, Margulis' biological/evolutionary approach is based on the fundamental role of primitive germs that appeared in the Archean and provoked life on Earth, which largely contributed to maintaining the physical-chemical atmospheric conditions that were suitable for life on the planet. Consequently, the Margulis approach puts an emphasis on evolution and autonomy in Earth's history.

Freelance journalist Jeanne McDermott (1989), in her profile of Lynn Margulis, states that Margulis is an authority on microcosms, thus providing "the biological ammunition" for Gaia, and remains its staunch advocate although she does little work on it directly. As a matter of fact, Margulis affirms, "I've concentrated all my life on the cell", and again: "life does not passively adapt, rather, it actively, "unknowingly", modifies its own environment". Furthermore, Lynn Margulis complains about the reductionist view of established science, which considers biology as a subfield of chemistry and physics. Taken to its extremes, "notably in the writings of Richard Dawkins, the machine-like image of a selfish replicator becomes synonymous with life itself. I contrast this prevailing neoDarwinian belief with a life-centered alternative worldview, called autopoiesis". As for Gaia, Margulis affirms "Gaia is more a point of view than a theory".

In fact, from 1989 on, Margulis (1989) forced Lovelock to restate the Gaia postulates. "Cybernetic systems are steered: biological cybernetic systems are steered from inside....The Gaia hypothesis postulates a planet with biota actively engaged in environmental regulation and control on its own behalf". Margulis' conceptual position supports, on one hand, the "for" present in one of the earlier papers (Lovelock and Margulis 1974). This attracted severe criticism, in particular from Kirchner (2003), who accused Lovelock of a teleological sin against science. On the other hand, she mediates transitions from Lovelock's first-orde cybernetics into a second-order cybernetics.

In second-order parlance, Gaia acquires the operational autonomy of a self-referential system (Clarke 2009). Second-order cybernetics is aimed in particular at these characteristics of natural systems, where circular recursions constitute the system in the first place. Natural systems are now described as at once environmentally open (in the non-equilibrium thermodynamic sense) and operationally (or organizationally) closed. Their dynamics are autonomous, that is, self-maintained and self-controlled. This recursive interplay of external openness and internal

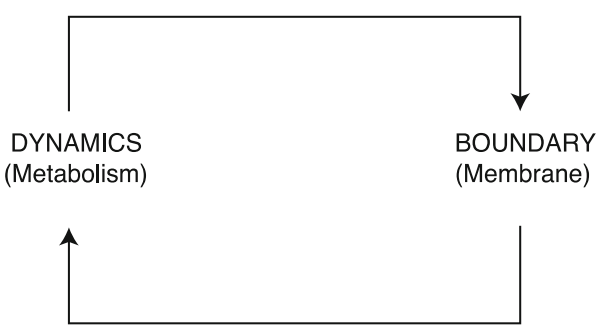

Fig. 1 Autopoietic recursion in the cell where the organization must remain invariant (otherwise the organism dies) and metabolism is nothing other than a biochemical instantiation of autopoietic organization; where one important feature is the boundary, which is created by the internal network of reactions. Adapted from Maturana and Varela (1980)

operational closure is precisely the mark of autopoiesis theory, originally proposed by Humbert Maturana and Francisco Varela at the outset of the second-order cybernetics era (Maturana and Varela 1980) (Fig. 1).

It is Margulis who introduced autopoietic theory most directly into Gaia science, to the extent of presenting Gaia as "the autopoietic planet where the biosphere as a whole is autopoietic, in the sense that it maintains itself. In our view, planet autopoiesis is the aggregate, emergent property of the many gas-trading, gene-exchanging, growing and evolving organisms in it" (Margulis 2000). In her enthusiastic openness to an autopoietic theory of life, Margulis (2001) accepted an even more impressive notion of cognition as necessarily involved in the event of life, at the lowest level of life, such as isolated cells.

However, even in a field of research that attempts to reproduce empirical models of autopoietic cells, Luisi (2003, 2006) and Bourgine and Stewart (2004) independently argue that a cognitive property in cells is not necessary for the simple autopoietic process. Conversely according to Varela, these authors affirm that the need for cognition becomes probably indispensable in order for the cell to definitively achieve the living state.

In any case, if the existence of a cognitive property at the minimal level of life (isolated cells) is plausible, then it is hard to imagine a similar complex property at the level of Gaia, an infinitely larger expression of life. In this respect, Thomson (Thomson 2001), while referring to a long and spirited conversation between Varela and Lovelock, remembers that Varela denied Gaia having any cognitive properties. On the other hand, Varela conceded to Gaia the property of autonomy, whose fundamental organization corresponds to operational closure. Varela concluded that "application of the concept of autonomy might liberate Gaia theory from some of the more animistic notions that have parasitized it". Furthermore, Varela criticized "the heuristic limitations of the Daisyworld model, in claiming that its feedback mechanisms are linear, in their hovering around an invariant homeostatic set of points". 
In conclusion, it is hard to affirm that Gaia theory has obtained substantial advantages from the opening to the autopoiesis hypothesis, beyond a few gains regarding the property of autonomy and perhaps evolution. We think it possible that Margulis cleverly noted the weakness of the Gaian construct, mainly regarding the origins of planetary life and its evolution. She used autopoiesis, with its contextual property of cognition being behind the origin of life, at least at the elementary level of the cell. At the same time, Margulis was perhaps trying to reinforce her symbiogenetic theory about the origin of germs and microorganisms. The latter, by definition, is based on the mutualistic exchange of pieces of cytoplasmatic material and pre-genic material (rybozimes) between primitive symbiontic elements. Such processes, however, probably do not require any cognitive properties in that they may be mediated by sensory input or actions compatible with the basic laws of physics and chemistry.

In addition, a large gap is opened between Margulis' meaning of cognition and that developed by Varela's later works. The latter introduced the equation: cognition equals intentionality, as a primitive sense-making property of autopoiesis and living entities ("living", meaning sense making). Here, the teleological character inherent in the notion of cognition appears in a very attenuated form. Varela (Weber and Varela 2002) admits to there being a residual form of teleology within the notion of intentionality, as inherent to life, but which does not, however, "require an extra, transcendental source, as in Kant". 10 Conversely, Margulis does not hesitate to introduce the

\footnotetext{
${ }^{10}$ In this paper published posthumously, Varela borrows the concept of intentionality from the phenomenological thought mainly of Sigmund Husserl to introduce it in the organization of the complex cellular autopoietic processes. Husserl (1950)—in opposition to Descartes who gives the human mind the unique and exclusive capacity to comprehend natural phenomena-introduces the idea of intentionality. Intentionality is intended as possibility/predisposition of man to open himself and be able to correspond to the events of nature as they appear, in his words: "to go to the things themselves", without Kantian a priori that is assumptions and prejudices. Again: "the phenomenological knowledge is always the conscience-world, intentional phenomenology, correlation subject-object and not conscience-thought that is knowledge without world. It defines the horizon of the world itself". In brief, Husserl substitutes the absolute knowledge of things ("clear and distinct ideas" in Descartes words) with awareness, consciousness of natural phenomena. Clearly, Varela, in applying the property of intentionality to the elements present in the interior of the cell and to the cells inside the living organism, confers to the intentionality a constitutive, that is ontological, value and not only a gnoseologic meaning. In brief, Varela hypothesizes that individual intracellular entities and the cells themselves could open up to each other and so contribute to the auto-organization of life. Unfortunately, the term intentionality is rather misleading, especially for people of Latin origin, because it should, ironically, be substituted by unintentionality according to, for example, the Roman law (jus romanum) which defines a human intentional act as an act carried out with full consciousness and will to do it.
}

teleological principle in biology, stating that "bacterial components fused via symbiogenesis are already conscious entities" (Margulis 2001). Here, Lynn Margulis appears to be more catholic than the Pope.

\section{Final considerations}

We would like to conclude this review with a few final thoughts about Gaia and its mentors.

a. Today, Gaia may appear as a less teleological and more plausible construction than at the time of its formulation. This is the case particularly with regard to the role played by biota and the biosphere in regulating the characteristics of the atmosphere and perhaps in optimizing it for the maintenance of life. For example, at the least, in part, humans' and other living beings' by-products released into the environment may come back through long feedbacks in a form that is useful to producers (Wilkinson 1999; Volk 2004). Furthermore, at the least, in perspective, synthetic biology could produce non-natural forms of matter and energy that return from the environment, through short and long feedbacks that are useful for the biosphere. For example, the DNA could be synthesized and engineered into $E$. coli for bacterial production of food supplements and cheap biofuels (Schmickle 2009).

b. Similarly, the persistent critique to the Gaia theory, with its homeostatic (regulation and maintenance) rather than evolutionary emphasis on the nature of the planet, can be at least partially downgraded from the present extension and conversion of the mechanisms of feedback between biota and the environment. This would result in a shift from the strictly engineeringphysiological approach characteristic of Lovelock to Margulis' biological evolutionary one.

c. This does not mean that the entire Gaian construct, independently of Lovelock's opinion, has the characteristics of modern holistic models. The latter are based on the self-organization and selection of dynamic systems containing an extremely large number of coupled elements and attractors, such as those proposed by Morowitz (1968), Bak et al. (1988) and Kauffmann (1993). These authors agree that entropy maximization and free energy minimization (negative entropy), common to living and (sometimes) inanimate matter, although playing an important role in the maintenance of homeostatic conditions on the planet, alone, however, do not assure the survival and evolution of the planet. For these reasons, the same authors attribute these fundamental characters to the planet self-organizational properties. From here, they 
invoke their opening to the not yet defined fourth law of thermodynamics, according to which systems tend to self-organize. (Kauffmann 2000; Chassin and Posse 2004).

Today, according to the more complex models of systems theory, Lovelock's proposal of very different and complex realities (like the biosphere and the inert environment) concurring - in a unified and harmonious way-in the creation of a supersystem may be both unexpected and provocative (von Bertalanffy 1968; Luhmann 1984).

The character of structural and functional antagonism between the two components that make up the system in its whole appears particularly clear, mainly when the autopoietic theory, in which Margulis merges the Gaia hypothesis, is applied to a sociological system. Luhmann (1984), a bourgeois sociologist who however uses the Marxist notion of social class struggles, based his analysis on the ineluctable contrast between the system-organized internally in several subsystems (economic, financial, executive, juridical, educational, health, etc.), each selfreferring and autopoietic_-and the environment, including inert nature and social and ethnic realities subjected to the system. In very concise terms, Luhmann, defined this kind of dynamics as "Mechanism des erwartens von Erwartungen" (mechanism to predict the expectations). In such a way, the environment's social claims may be tuned to become "compatible" with the needs and interests of the system: in practice, through the neutralization of the environmental ones. After all, if the autopoietic social system refers to the globalized planet, then it is hard to call it Gaia.

d. Finally, the physics support to the Gaian construction, centered on, and limited to, the properties of the second principle of thermodynamics, appears not to be reductive. Also, in Schrödinger's interpretation (1944) of thermodynamics in the stationary state, entropy does not ineluctably increase because of the dissipative properties of free energy in living matter (concept of negative entropy). ${ }^{11}$ Alternatively, in the area of dynamic systems theory, Juarrero (1999) proposed that "context-sensitive, thermodynamic constraints operating in an open system far from equilibrium such as auto catalytic cycles, decrease the rate at which local entropy is produced". In this way, living matter would guarantee its survival.

\footnotetext{
11 Negative entropy is the reverse of entropy $(1 / S)$ according to the elegant equation by Ludwig Boltzmann that expresses the entropy $(S)$ as probability $S=k(\ln P)$, where $k$ is the Boltzmann constant and $P$ the probability of an event.
}

Thus, Lovelock, mentor of the living Earth, did not pose, on the one hand, the problem of the emergence of life and what relationship this process could have had with inert nature, and on the other, if it could be possible to propose a global approach to study the entire planet on a physical basis today.

Some support to both of these questions could come from the pervasive modern physics, in particular quantum mechanics. Lovelock knew that the major atomic physicists, Schrödinger (1944), Bohr (1965) and Heisenberg (1958), agree that quantum principles have given the basis for the knowledge of the inert and living matter and precisely located analogies and differences between the emergence of the quantum event and of the phenomena of life. These issues, in fact, were clear in the mind of Gould (1984): "First, nothing in biology contradicts the laws of physics and chemistry; any adequate biology must be consonant with the basic sciences. Second, the principles of physics and chemistry are not sufficient to explain complex biological objects because new properties emerge as a result of organization and interaction. These properties can only be understood by the direct study of the whole living systems in their normal state."

Heisenberg (1958) had provided the basis for such statement arguing that living components and inert ones are made of the same matter, that is, matter of the same nature. The only thing differentiating living organisms are the connections within matter itself. ${ }^{12}$ The world that was previously divided into different groups of objects is now divided into different connecting groups that perhaps transcend chemistry and physics. In his words, "To comprehend life, it is probably necessary to go beyond quantum theory and to build a new, coherent series of concepts, whose physics and chemistry can be an limiting case. An essential part of this series of concepts and notions, could be the history of perception, adaptation, organ function and intentionality. If this hypothesis is correct, the combination of Darwin's theory with physics and chemistry will not suffice to explain organic life".

On this issue, the problem of connection inside the same matter and the apparent cooperation of physical-chemical mechanisms and nonphysical-chemical entities in the construction of life, Bohr (1965) sees a kind of idea of

\footnotetext{
12 The ultimate structural difference between inert and living matter is the same that exists between periodic solids and aperiodic ones. In particular, the difference is between the rigid repetition of isomeric atomic structures in periodic solids in contrast to internally differentiated isomers in living matter. According to Schrödinger (1944), this molecular organization of living matter could be related to some kind of molecular genetic code leading to the formation of structurally and functionally distinct molecules and cells in living beings.
} 
purposiveness outside physics and chemistry (not substantially different from the notion of intentionality expressed by Varela). He also sought that biological research often refers to a unitary aspect and purposeoriented reactions apparently linked to self-regulating processes. Bohr, furthermore, argues that, in general, mechanistic and purpose-oriented behaviors are not contradictory points of view, but have a complementary relationship, in the sense that they can be studied one by one within the context of the whole system. The principle of complementarity, however, is not easily applicable to living organisms, in which, in order to investigate their purpose-oriented component, one would have to destroy the structural, organic one, that is to say, to kill the cell or the organism itself.

Furthermore, another possible support to Lovelock's approach to the comprehension of the planet as a whole comes from quantum mechanics with Byrne (2011). He recently identifies entanglement ${ }^{13}$ as the most important discovery of quantum physics, in that it allows for the knowledge of everything there is to know about a composite system, without knowing everything about the individual constituent. This is a good example of how we are simply not biologically equipped for abstraction and it upsets our sense of reality. He shares this view with Vedral (2011).

Heisenberg (1958), with regard to this subject, and affirms that both in quantum and classical physics all observable things and phenomena are the same thing. The difference lies in the way of interpreting the nature of reality, which for realist physical scientists, including Einstein, is the state of reality, while for the anti-realists, like Bohr and himself, "it is in the potentiality of states, expressed as coexisting states, where potentiality is plausible, since one potentiality can imply others or their overlapping". Heisenberg borrowed these terms from his assistant Victor von Weizsäcker, follower of Martin Heidegger, the famous author of Being and Time (Heidegger

\footnotetext{
${ }^{13}$ Entanglement is a quantum phenomenon in which two or more particles, once having interacted, remain inexorably linked no matter how far apart they are, because they form just a single two-particle system, and not two one-particle systems as established by classical physics, including relativity theory. That is, the state of particles remains entangled, unless they interact with another system. Furthermore, such at distance events present uncertainties both in ontological and gnoseologic sense and their predictions become possible only on statistical and probabilistic basis emerging from the observed outcomes. At this point, physicists are no longer detached observers and spectators, nor are they "prescriptive" dictators, but participants in transactions ("wechselpiel" in Heisenberg's words), between man and nature shrouded by relationships of uncertainty. In this sense, Seigfried (1990) suggested that "only through such transactions in all areas of life, as simplified by the experimental performances of physicists, can we really have a say in the making of the laws which determine our form of life and give ourselves laws at last".
}

1927). Through him, Heisenberg started a long and fruitful exchange with Heidegger ${ }^{14}$ (Brocchieri 2006).

In addition, it seems to us that there are certain possible analogies between the emergence of the quantum event and that of life, in that both events seem to rise from the nothingness of matter (Aitchison 1985; Close 2009; Byrne 2011; Deacon 2012). This is possible because quantum nothingness is not Talete's absolute nothingness, from which nothing could have been born, but it is a fullness of radiation and particles (electrons, photons and quarks). These entities, in their continuous motion, may be capable of producing such threshold levels of energy as to induce the creation of atoms. The latter are then capable of combining into molecules and then into inert or living matter.

Another apparent analogy with life is that quantum phenomena, at least on the macro world level, seem to involve the observer when they emerge, impeding a description of the event itself. This leads to the quantum paradox of the need for observing the observer, the latter being involved in the quantum phenomenon (Vedral 2011).

A similar difficulty is found by man in defining the sense of life and, in particular, certain aspects regarding psychological activity, including self-consciousness, since the

\footnotetext{
${ }^{14}$ We believe it is not accidental that the anti-realist thought of physicists, such as Niels Bohr, would have been deeply influenced by Kierkegaard's Danish existentialism through the mediation of Harald Øffding, and Werner Heisenberg (WH) would be influenced by, and in turn, influencing the ontologic phenomenology of Martin Heidegger $(\mathrm{MH})$. In short, the more radical existentialistic-phenomenological thought (MH's) and quantum thought (at the least in the Copenhagen interpretation) appear to have the following points in common:
}

a. The notion of reality moving from that of material substance (res extensa in Descartes) to that of event/phenomenon (Ereignis in Heidegger 1927), that is, of phenomenon as event (Gadamer 2005; Rosen 2008).

b. The emergence of the event seems to require that the human observer has to take a step backward (Schritt Zurück in Heidegger 1979) from his condition of Ego-cogitans et faber ("the man who thinks and does" in Descartes), in order to open himself up ( $D a$ sein in Heidegger 1972) and let nature's phenomenon to be, that is, to the world of operating the "appropriation" of time, space and reality that Western man took away. In this way, these entities become time, space and reality in the World in its manifestation.

c. The same human observer is involved in the event and loses the capability to describe and interpret reality. It is a reality that quantum physics expresses as uncertainty and so its predictions can be expressed only in terms of the probability that something could appear.

d. In brief, the phenomenological thought grasps reality as "possibility": "above reality there is possibility", (Heidegger 1963) and quantum physics as "potentiality" (Newton 2009).

Here, physics and non-analytic philosophy seem to converge-the convergence consisting in overcoming Cartesian physics and philosophy, that is, modern science and metaphysics-although remaining on different and distant mountains, because physics requires experimental proof, not pure speculative thought. 
human mind perceives itself to be both subject and object in the description and comprehension of these events. A sort of circular causality replaces linear causality in a way that sign and sense are at the same time either cause or effect.

Lovelock (and the same can be said for Margulis) does not seem to have found it necessary to introduce quantum theory in his description of the structure/function of the living planet, nor did he find possible analogies between the quantum world and life.

As a consequence, in our view, the Gaian construct presents some sort of low profile for both the physical aspect and the heuristic and epistemic one.

In this way, James Lovelock and Lynn Margulis, independent and heretical authors of Gaia, appear above all to be realists, conservatives and orderly, in comparison to the same established science or at the least to the more innovative and advanced interpretative criteria of reality.

Acknowledgments We are most grateful to Drs. Mary Howard Cooper and Giulia Onori who detected-and thus enabled us to correct-numerous typographical fluctuations as well as genuine errors, obscurities and confusions.

Open Access This article is distributed under the terms of the Creative Commons Attribution License which permits any use, distribution, and reproduction in any medium, provided the original author(s) and the source are credited.

\section{References}

Aitchison IJR (1985) Nothing's plenty. The vacuum in the modern quantum field theory. Contemp Phys 26:333-391

Azzone GF (2010) The second evolution: after the genes the cultural birth. Rend Lincei 21:283-299

Bak P, Tang C, Wiesenfeld K (1988) Self organized criticality. Phys Rev A 38:364-374

Bohr N (1965) I quanti e la vita. Bollati Boringhieri, Torino

Boulding KE (1965) The image. University of Michigan Press, Ann Arbor

Bourgine P, Stewart J (2004) Autopoiesis and cognition. Artif Life 10:327-345

Brocchieri A (2006) L'evento, Heidegger, Heisenberg e l'Ereignis, Sapere e Linguaggi a confronto. http://www.asia.it/adon.pl?act= doc $\&$ doc $=369$

Byrne P (2011) Leonard Susskind: the bad boy of Physics. Scientific American

Chassin DP, Posse C, Malard J (2004) Managing complexity. http://arxiv.org/abs/nlin/0408051

Cherniak C (2005) Innatneness and brain-wiring optimization: non genomic nativism. In: Zilhao A (ed) evolution, rationality and cognition: a cognitive science for the twenty-first century. Routledge, London

Clarke B (2009) Neocybernetics of Gaia. In: Crist E, Rinker HK (eds) The emergence of second-order Gaia theory, Gaia in turmoil. MIT Press, USA

Close F (2009) Nothing. A very short introduction. Oxford University Press, USA
Deacon TW (2012) Incomplete nature: how mind emerged from matter. Norton, USA

Ducluzeau AL, van Lis R, Duval S, Schoepp-Cothenet B, Russel MJ, Nietschke W (2008) Was nitric oxide the first deep electron sink? Trends Biochem Sci 34:9-15

Gadamer HG (2005) Heidegger and Heisenberg: is a letheia another word for quantum theory? Anglican + Calvinist. http:// anglicancalvinist.blogspot.com/2005_08_01_archive.html

Gould SJ (1984) Size and shape. Natural History, Jan 1984

Haken H (1975) Cooperative phenomena in systems far from thermal equilibrium and in non physical systems. Rev Mod Phys 47:91-121

Harvey HW (1957) The chemistry and the fertility of the sea waters. Cambridge, London

Heidegger M (1963) Mein Weg in die Phänomenologie. Quoted by Franco Volpi 1988, L'Approccio fenomenologico alla storia della filosofia nel primo Heidegger. Aut-Aut, 223-234, pp 203-230

Heidegger M (1972) On time and being. Harper and Row Inc., USA

Heidegger M (1979) Prolegomena Zur Geschichte des Zeitebegriffs, (Gesamtaus Gabe. Vol. 20, 1979), Klostermann, Frankfurt. M. Heidegger 1988, L'Intenzionalità: Tr. it. R. Cristine. Aut-Aut 223-234:15-17

Heidegger M, Sein und Zeit (1927) Max Niemeyer, Tubingen. M.Heidegger 1976, Essere e Tempo, Tr. it. P. Chiodi, Longanesi, Milano

Heisenberg W (1958) Physics and philosophy. Allen and Unwin, London

Husserl S (1950) Die idee der phanomenologei. M. Nijhofft. The Hague, Husselrl, S. 1965, Idee per una fenomenologia pura e per una filosofia fenomenologia, Libro I, trad. It., G. Alleney, Einaubi Torino

Hutton J (1794) An investigation of principles of knowledge and of the progress of the reason: from sense to science and philosophy. Thoemes Press, Bristol

Huxley, Thomas H (1887) On the reception of the 'Origin of Species'. In: Darwin F (ed) Life and letters of Charles Darwin. John Murray, London

Juarrero A (1999) Dynamics in action, intentional behavior as complex system. The MIT Press, Cambridge

Kauffmann SA (1993) The Origins of Order, Oxford University Press, USA

Kauffmann SA (2000) Investigations. Oxford University, Oxford

Kimura M (1983) The neutral theory of molecular evolution. Cambridge University Press, London

Kineman JJ (1997) Toward a special and general theory of autevolution. Bear Mountain Institute, Boulder

Kirchner JW (1989) The Gaia: can it be tested. Rev Geophys 27:223-235

Kirchner JW (2003) The Gaia hypothesis: conjectures and refutations. Clim Change 58:21-45

Kleidon A (2002) Testing the effect of life on Earth's functioning: how Gaian is the Earth system? Clim Change 52:383-389

Kleidon A, Fraederich K (2004) Biotic Entropy production and global biosphere-atmosphere interactions. In: Kleidon A, Lorenz RD (eds) Non equilibrium thermodynamics and the production of entropy. Springer, Berlin, p 260

Kump LR (2009) A second opinion for our planet. Science 325:539-540

Lenton TM (1998) Gaia and the natural selection. Nature 394:439-447

Lenton TM (2002) Testing Gaia: the effect of life on Earth's habitability and regulation. Clim Change 52:409-422

Lenton TM, Wilkinson DM (2003) Developing the Gaia theory. Clim Change 58:1-12

Lewontin RC (1998) Gene. Organismo e ambiente, Editore Laterza 
Lovelock JE (1988) The Ages of Gaia — a biography of our living Earth. Norton, USA

Lovelock JE, Margulis L (1974) Atmospheric homeostasis by and for the biosphere: the Gaia hypothesis. Tellus 24:2-9

Luhmann N (1984) Soziale Systeme. Grundriß einer allgemeinen Theorie, Surkamp Verlag. Frankfurt, ammMein. Luhmann, N., 1990, Sistemi sociali, trad. It. A. Febbrajo. Il Mulino, Bologna

Luisi PL (2003) Autopoiesis: a review and a reappraisal in: naturwissenschaften. Springer 90(2):49-59

Luisi PL (2006) The origins of life. Cambridge, London

Margulis L (1991) Symbiogenesis and symbionticism. In: Margulis L, Fester R (eds) Symbiosis as a source of evolutionary innovation. The MIT Press, Cambridge, pp 1-14

Margulis L (2001) The conscious cell. Ann NY Acad Sci 929:1-16

Margulis L, Lovelock JE (1989) Gaia and geognosis. In: Rambler MB, Margulis L, Fester R (eds) Global Ecology: toward a science of the biosphere. San Diego Academic Press, San Diego

Margulis L, Sagan D (2000) What is Life. University of California Press, USA

Maturana HF, Varela FJ (1980) Autopoiesis and cognition: the realization of the living. In: Cohen RS, Wartofsky MW (eds) Boston studies in the philosophy of science 42. D. Reidel Publishing Co., Dordecht

McDermott J (1989) A biologist whose heresy redraws Earth's three of life, Smithsonian Magazine, August 1989

Morowitz H (1968) Energy flow and biology: biological organization as a problem in thermal physics. Academic Press, NY

Newton RG (2009) How physics confronts reality, Einstein was correct but Bohr won the game. World Scientific Publishing, London

Oreskes N, Shrader Frenchette K, Belitz K (1994) Verification, validation, and confirmation of numerical models in the Earth sciences. Science 263:641-646

Platt JR (1964) Strong inference: certain systematic methods of scientific thinking may produce much more rapid progress than others. Science 346:347-353

Rosen SM (2008) Quantum gravity and phenomenological philosophy found. Physics 38:556-582

Sapp J, Carrapico F, Zolotonosov M (2002) Symbiogenesis: the hidden face of constantin Merezhkowsky. Hist Phil Life Sci 24:413-440

Sarà M (1994) L'olismo, la teoria dell'evoluzione e la chiave lamarckiana. In: Chiarelli B, Chiarelli I, Margulis L, Morchio R, Sarà M, Scannerini S (eds.) Biologia Teorica. EDO. Jaca Book, Milano, pp 109-139
Scannerini S (1995) Evoluzione e simbiosi. In: Luzzatto M, Maggiora P, Scalfari M (eds) Biologia evoluzionistica. Tessere. CUEN, Napoli, pp 85-96

Scannerini S (2003) Il paradigma di gaia. http://www.intelligen zartificiale.com/paradigma_gaia.htm

Schmickle S (2009) While Darwin observed evolution, synthetic biologists are learning to control it, Interview with SchmidtDannert. http://www.minnpost.com/stories/2009/)

Schneider SH (2001) A goddess of Earth or the imagination of man? Science 291:1906-1907

Schrödinger E (1944) What's life. Cambridge University Press, USA

Seigfried H (1990) Autonomy and quantum physics: Nietzsche, Heidegger and Heisenberg. Phil Sci 57:319-330

Shannon CE, Weaver W (1949) The mathematical theory of communication. University of Illinois, Urbana

Smith MJ, Szathmáry E (1997) The major transitions in evolution. Oxford University Press, USA

Sonea S (1993) Le strutture biologiche: Batteri, EDO. Jaca Book, Milano

Spenser H (1893) The inadequacy of natural selection. Contemp Rev 64:153-166

Thom R (1989) Structural stability and morphogenesis: an outline of a general theory of models. Addison-Wesley, Reading

Thomson IW (2001) Gaia 2: emergence. The New Science of Becoming

Tsang CF (1991) The model process and model validation. Groundwater $29: 825-831$

Vedral V (2011) Living in a quantum World. Scientific American

Volk T (1998) Gaia's body-Toward a physiology of the Earth. Copernicus

Volk T (2004) Gaia is life in a wasteworld of by-products. In: Schneider SH, et al. (ed) Scientists Debate Gaia. MIT Press, USA, pp 27-36

von Bertalanffy L (1968) General system theory. Foundations, development, applications. George Braziller, New York

Weber A, Varela FJ (2002) Life after Kant: natural purposes and the autopoietic foundations of biological individuality. Phenomenol Cogn Sci 1:97-125

Wilkinson DM (1999) Is Gaia really conventional ecology? Oikos 84:533-536

Wilson EB (1928) Protoplasm. It's composition and structure. In: The cell in development and heredity, 3rd edn. Macmillan Company, New York 